\title{
Blood Cell Polyamines in Children with Short Stature in Reference to Growth Hormone Activity
}

\author{
S. LEISTI, J. PERHEENTUPA, ${ }^{(22)}$ H. K. ÅKERBLOM, AND M. A. SIIMES \\ Children's Hospital, University of Helsinki, Helsinki, Finland
}

\section{Summary}

The molar ratio of two blood polyamines (spermidine to spermine) was investigated in $\mathbf{5 4}$ children with shortness of stature. The long-term reproducibility of this ratio was $\mathbf{9 . 0 \%}$. In children with no endocrine disturbances, the mean ratio was 0.97 . In children with isolated growth hormone deficiency, it was 0.61 , and in those with growth hormone and ACTH deficiency, it was 0.67 , both significantly low values. The ratio showed a significant positive correlation with growth hormone response to insulin hypoglycemia $(r=0.58 ; P<0.001)$ and with the nitrogen retention response to short-term growth hormone therapy $(r=0.45 ; P<0.001)$. In contrast, no such correlation was present with cortisol response to hypoglycemia.

\section{Speculation}

The association of decreased growth hormone activity with decreased polyamine synthesis in man agrees with data obtained in vitro and in animals. Growth hormone seems to be a direct regulator of the synthesis of polyamines, which have essential functions in cellular metabolism.

Three polyamines, putrescine, spermidine (SPD), and spermine (SP), are associated with several biochemical events of tissue growth, including protein and nucleic acid synthesis and metabolism. The initial and rate-limiting enzyme in the synthesis of these amines is ornithine decarboxylase (ODC). According to animal experiments, its activity in tissues appears to be influenced by growth hormone $(\mathrm{GH})$ activity. The induction of ODC activity results in an accumulation of SPD and a consequent increase in the molar ratio of SPD to SP (SPD/SP) in tissues (8).

We determined SPD/SP as an indirect measure of the rate of polyamine synthesis in blood cells (9) in a group of children with short stature, with or without evidence of impaired GH secretion, to assess the role of $\mathrm{GH}$ in human polyamine metabolism.

\section{SUBJECTS AND METHODS}

A total of 54 children, 23 girls and 31 boys, aged from 5.2 to 18.5 years, were investigated because of short stature: height more than 2.5 S.D. below the mean for age (1) (Table 1).

GH deficiency was defined as a repeatedly subnormal plasma GH response to insulin test (highest level below $7.0 \mathrm{ng} / \mathrm{ml}$ ). ACTH deficiency was defined as a repeatedly subnormal plasma cortisol response to insulin test (highest level below $26 \mu \mathrm{g} / 100 \mathrm{ml}$ ) (13) in the presence of other evidence for hypopituitarism. Using these criteria, three groups of patients were formed as follows: (1) isolated GH deficiency: 17 children (11, idiopathic; 5 , birth in breech or face presentation or severe maternal toxemia; 1 , craniopharyngeoma); (2) GH and ACTH (and cortisol) deficiency: 8 children (5, breech presentation or asphyxia at birth; 2 , craniopharyngeoma; 1, idiopathic). The children with craniopharyngeoma were having cortisol substitution, 7.5 to $15 \mathrm{mg} / \mathrm{m}^{2}$ daily; it was discontinued on the day preceeding the insulin test. All 8 children also had thyroid-stimulating hormone deficiency; this was appropriately substituted for with thyroxin during the study; (3) short stature without endocrine deficiency: 26 children [19, familial short stature and/or delayed growth and maturation; 3, prenatal growth retardation; 2, Turner's syndrome; 1, autosome anomaly [46, XY, (9)]; 1, cartilage-hair hypoplasia]. These children formed the reference group. Data on 3 additional children were included in the correlation analyses (1, primary autoimmune adrenalitis; 2, primary hypothyroidism).

The polyamine concentrations were determined from the sediment of blood including all cellular elements. Erythrocyte counts were in all patients within normal limits. Heparinized venous blood samples of about $10 \mathrm{ml}$ were drawn after an overnight fast, centrifuged immediately, and assayed (9). The results were expressed as the molar concentration ratio, SPD/SP, to curtail the effect of errors due to variation in dilution in the analysis (9). The combined biological and technical reproducibility of the ratio was examined by restudying 29 of the children after periods from 1 to 12 months (Fig. 1). No changes in medication took place during

Table 1. Data on children with short stature

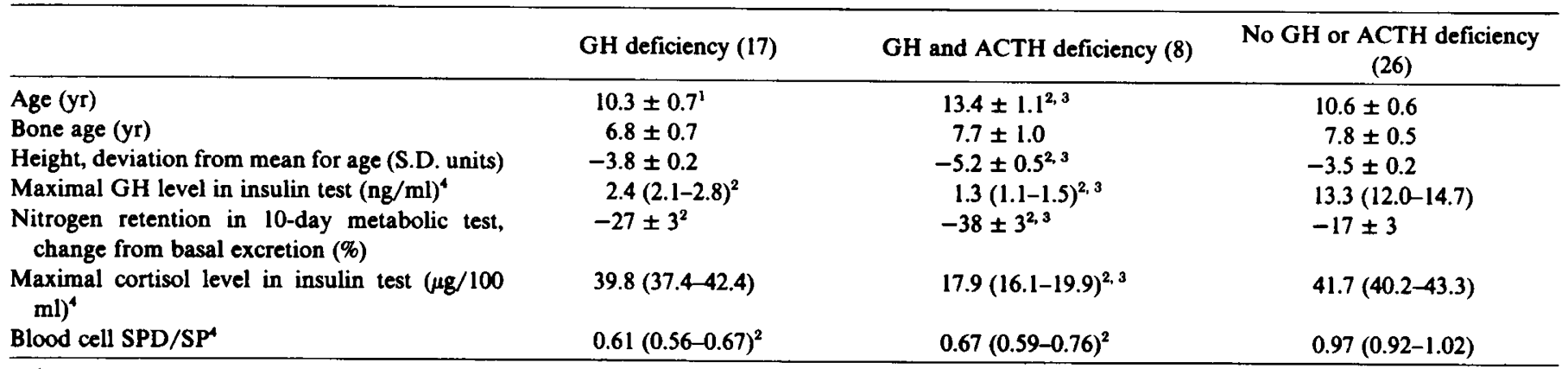

\footnotetext{
'Mean \pm S.E.

${ }^{2}$ Significantly $(P<0.05)$ different from patients without GH deficiency (group 3$)$.

${ }^{3}$ Significantly $(P<0.05)$ different from patients with isolated GH deficiency (group 1$)$.

${ }^{4}$ Calculated after log transformation.
} 
the interval. The SPD/SP ratio showed a precision of $9.0 \%$. [The figure is the S.D. of the distribution of the percentage of intrapair differences, $100(b-a) /(b+a)$, where $a$ is the first and $b$ the second value of an individual (13)]. There was no correlation between the SPD/SP and the white blood cell counts.

Blood cell SPD/SP was also compared with the GH activity, determined as the nitrogen retention response to a 5-day $\mathbf{G H}$ treatment, $2 \mathrm{mg} / \mathrm{m}^{2}$ IM daily (15). The activity of the GH preparation (18) used was determined with the tibia test in hypophysectomized infantile rats. It gave a mean rat tibial width of $237 \mu \mathrm{m}$, compared with $225 \mu \mathrm{m}$ after USP bovine GH standard and 163 $\mu \mathrm{m}$ after saline (courtesy of Dr. Olaf Trygstad and Irene Foss, Pediatric Research Institute, University of Oslo). Plasma GH was determined with an radioimmunoassay and cortisol with a fluorometric method (13). Urinary nitrogen was measured with an automatic Kjeldahl analyser.

The distributions of the values of maximal plasma GH and maximal plasma cortisol concentration (in insulin test) and SPD/ SP of blood cells were positively skewed. To correct for the skewness, mean values + S.E. were calculated after a $\log$ transformation of the values. The mean values were compared with

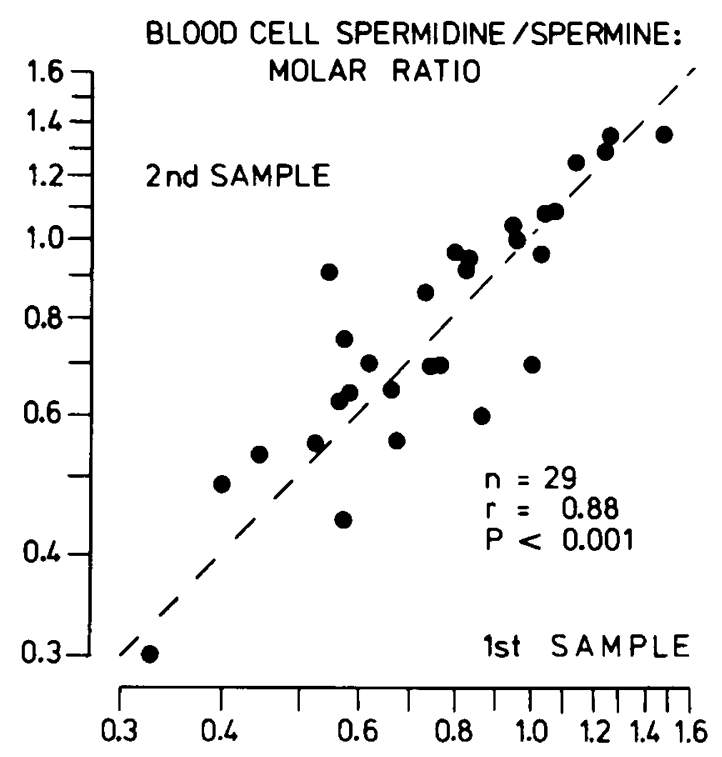

Fig. 1. Reproducibility of blood cell spermidine/spermine molar ratio (SPD/SP) in 29 of 54 children.
Student's two-tailed $t$ test. Correlation coefficients were caĺculated with standard methods.

\section{RESULTS}

The mean blood cell SPD/SP of the 25 hypopituitary children (groups 1 and 2, Table 1) was significantly decreased $(P<0.001)$. It was similar in the groups with isolated $\mathrm{GH}$ and $\mathrm{GH}$ and $\mathrm{ACTH}$ deficiency. The mean values of SPD/SP were 63 and $69 \%$ of the mean of the reference group, respectively.

The SPD/SP ratio showed a correlation with the maximal plasma GH level of the insulin tests and with nitrogen retention response to $\mathrm{GH}(P<0.001$, Fig. 2$)$. It showed no correlation with the maximal plasma cortisol level of the insulin test.

In the reference group, SPD/SP depended neither on chronological age nor on bone age. The values were slightly higher in girls (mean, 1.00) than in boys (0.94); this difference was not statistically significant.

\section{DISCUSSION}

In patients with growth hormone deficiency, blood cell SPD/ SP was lower than in children with nonendocrine short stature. In the latter, the ratio was similar to or slightly lower than that found in healthy individuals (4). These findings indicate that a decrease in polyamine synthesis is associated with $\mathrm{GH}$ deficiency. In animal experiments, GH and glucocorticoids and/or ACTH have been found to increase polyamine synthesis $(5,17)$. In our series, however, the coexistence of hypocortisolism with GH deficiency was not associated with a further decrease in the polyamine ratio.

The association between growth process and polyamine synthesis has been demonstrated in several situations. Thus, high activity of ODC and increased SPD/SP are present in tissues of rapidly growing young animals $(8,9)$, in regenerating rat liver $(10)$, in compensatory or adaptive hypertrophy of renal and cardiac tissue $(2,3)$, and in various tumors (8). Moreover, the circadian variation in renal ODC activity may be attributed to physiologic fluctuations in plasma GH levels in rats (14). Evidence for such physiologic association between GH activity and polyamine synthesis has also been found in human fetuses. After midgestation, the ODC activity in fetal liver parallels the rise and fall of plasma GH level $(6,11,19)$.

A causal nature of this relationship is indicated by several animal experiments. Hypophysectomy results in a decreased concentration of SPD in rat liver, and this effect is reversed by GH substitution (12). Pharmacologic doses of GH increase both the ODC activity, SPD concentration, and SPD/SP ratio in several
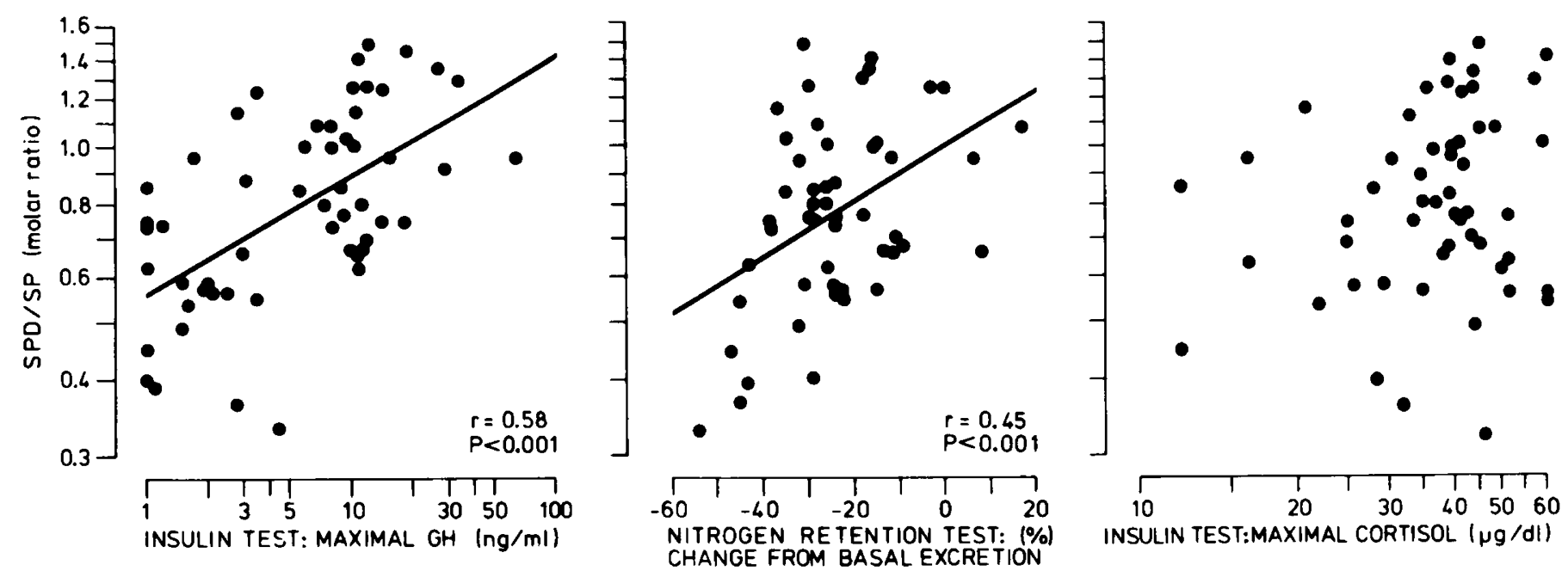

Fig. 2. Blood cell spermidine/spermine molar ratio in correlation to maximal plasma GH level during insulin test, nitrogen retention during a 5-day GH administration, and maximal plasma cortisol level during insulin test in 54 children with short stature. Significant correlations are indicated by respective regression lines. 
tissues (10). In contrast, treatment with an anti-growth hormone antiserum decreases the ODC activity in rat liver (16). All these pieces of evidence would be in accord with the hypothesis that GH activity is a major factor in determining the synthesis of polyamine under experimental conditions in animals. The effect does not seem to be mediated via stimulation of the somatomedin activity (7). Our findings suggest that the relationship may also exist in man and, further, suggest that growth hormone may play a similar role in the regulation of polyamine synthesis in man as in animals.

\section{REFERENCES AND NOTES}

1. Bäckström, L., and Kantero, R. L.: Cross-sectional studies of height and weight in Finnish children aged from birth to 20 years. Acta Paediatr. Scand. Suppl., 220: 9 (1971).

2. Brandt, J. T., Pierce, D. A., and Fausto, N.: Ornithine decarboxylase activity and polyamine synthesis during kidney hypertrophy. Biochim. Biophys. Acta, 279: 184 (1972).

3. Caldarera, C. M., Casti, A., Rossoni, C., and Visioli, O.: Polyamines and noradrenaline following myocardial hypertrophy. J. Mol. Cell. Cardiol., 3: 121 (1971).

4. Cohen, L. F., Lundgren, D. W., and Farrel, P. M.: Distribution of spermidine and spermine in blood from cystic fibrosis patients and control subjects. Blood, 48: 469 (1976)

5. Eloranta, T. O., and Raina, A. M.: S-adenosylmethionine metabolism and its relation to polyamine synthesis in rat liver. Effect of nutritional state, adrenal function, some drugs and partial hepatectomy. Biochem. J., 168: 179 (1977).

6. Guha, S. K., and Jänne, J.: Decarboxylation of ornithine and adenosylmethionine in rat ovary during pregnancy. Acta Endocrinol., 81: 793, (1976).

7. Holladay, L. A., Levine, J. H., Nicholson, W. E., Orth, D. N., Salmon, W. D. and Puett, D.: Evidence for structural dissociation of two biologic actions of growth hormone. Biochim. Biophys. Acta, 381 : 47 (1975).

8. Jäne, J., Pösö, H., and Raina, A.: Polyamines in rapid growth and cancer. Biochim. Biophys. Acta, 473: 241 (1978).
9. Jänne, J., Raina, A., and Siimes, M.: Spermidine and spermine in rat tissues at different ages. Acta Physiol. Scand., 62: 352 (1964).

10. Jänne, J., Raina, A., and Siimes, M.: Mechanism of stimulation of polyamine synthesis by growth hormone in rat liver. Biochim. Biophys. Acta, I66: 419 (1968).

11. Kaplan, S. L., Grumbach, M. M., and Auber, M. L.: The ontogenesis of pituitary hormones and hypothalamic factors in the human fetus. Recent Prog. Horm. Res., 32: 161 (1976).

12. Kostyo, J. L.: Changes in polyamine content of rat liver following hypophysectomy and treatment with growth hormone. Biochem. Biophys. Res. Commun., 23: 150 (1966).

13. Leisti, S., and Perheentupa, J.: Insulin test: precisions of and correlations between glucose and hormone responses. Acta Endocrinol., 88: 99 (1978).

14. Nicholson, W. E., Levine, J. H., and Orth, D. N.: Hormonal regulation of renal ornithine decarboxylase activity in the rat. Endocrinology, 98: 123 (1976).

15. Prader, A., Illig, R., Szeky, J., and Wagner, H.: The effect of human growth hormone in hypopituitary dwarfism. Arch. Dis. Child., 39: 535 (1964).

16. Rao, A. J., and Li, C. H.: Effect of antiserum to bovine somatotropin on ornithine decarboxylase activity of liver, kidney and brain of young male rats. Arch. Biochem. Biophys., 180: 169 (1977).

17. Richman, R., Dobbins, C., Voina, S., Underwood, L., Mahaffee, D., Gitelman, H. J., Van Wyk, J., and Ney, R. L.: Synergistic effect of cortisol and growth hormone on hepatic ornithine decarboxylase activity. Proc. Soc. Exp. Biol. Med., 138: 880 (1971).

18. Roos, P., Fevold, H. R., and Gemzell, C. A.: Preparation of human growth hormone by gel filtration. Biochim. Biophys. Acta, 74: 525 (1963).

19. Sturman, J. A., and Gaull, G. E.: Polyamine biosynthesis in human fetal liver and brain. Pediatr. Res., 8: 231 (1974).

20. Informed consent was obtained from parents of all children.

21. The authors are grateful to E. Vahvaselkä, Chem. Engineer, for preparing the growth hormone, and to L. Aulis, M. Sci, and the Water Conservation Laboratory, City of Helsinki, for nitrogen analyses.

22. Requests for reprints should be addressed to: Dr. J. Perheentupa, Children's Hospital, University of Helsinki, SF-00290, Helsinki 29, Finland.

23. This research was supported by the Medical Research Council of the Academy of Finland and from the Foundation for Pediatric Research, Helsinki, Finland.

24. Received for publication March 6, 1979.

25. Accepted for publication July 18, 1979. 